\title{
Zorwort.
}

O2eun id bex Ilufforderung des Berlages gefolgt bin, für Die

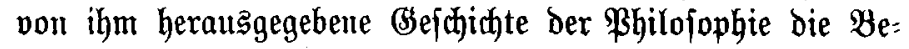

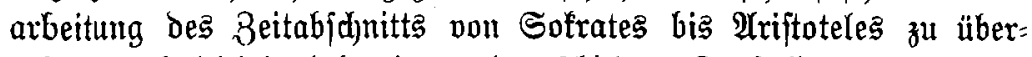
nebmen, obgheid Doch bereits zmei veridiedene Darftellungen der alten Bhiloiophie von mix vorliegen ${ }^{1}$ ), jo habe id bajür einen fubjeftiven und

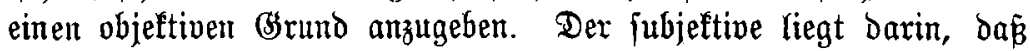
ich Dar lłberzeugung lebe, man fönne zur Einficht des Philojophen nux beranreifen, indem man jidh immer wieder erneut innerlich mit Den RTajfifern der griedijdes Bhilojophie auseinanderjebt. Den

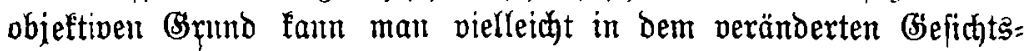
punlt finden, aus dem heraus in ben wertwollen Stoff bebandelt habe. Was mein Ziel bei biejem Unternebmen war, ift nidjt nur in Der (sinleitung umb im Sd)lupwort flar ausgejprod)en, jondern wird fich, wie ich hoffe, aud aus ber Darftellung ber Sehren der einzelnen Bhilofophes erfenten lafien.

\section{Walter Rinkel.}

1) 1. (Sefdidhte der Bhilupophie als Einleitung in das Snjtent der Philo= jophie (bis Blaton) (Erichienen bei $\mathfrak{A}$. Tüplmann, (Sießen) แnd 2. Angemeine (Sejdichte der Bhilojophie oder Entwidtung bes philofophifchen Gedantens oon Thales bis auf unjere 3eit. Bo. I (seift ber \$hilofophie bes Altertums

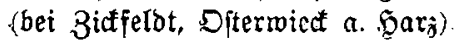


